\title{
Vorschläge und Berichte zur Reform des europäischen und deutschen internationalen Gesellschaftsrechts
}

Vorgelegt im Auftrag der zweiten Kommission des Deutschen Rates für Internationales Privatrecht, Spezialkommission Internationales Gesellschaftsrecht Hrsg. v. Hans J. Sonnenberger

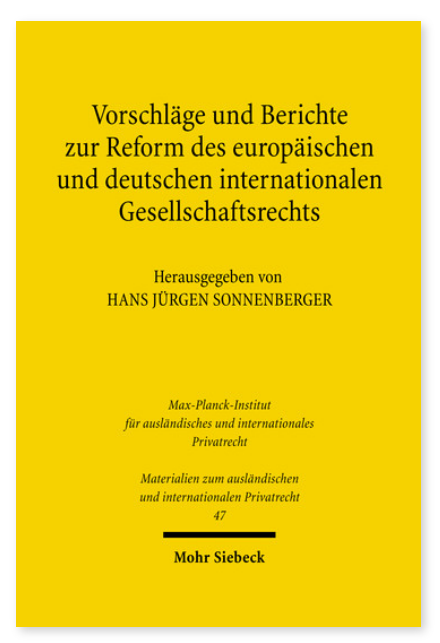

2007. XI, 625 Seiten. MatIPR 47

ISBN 978-3-16-151294-0

DOI 10.1628/978-3-16-151294-0

eBook PDF $139,00 €$

ISBN 978-3-16-149307-2

Leinen $139,00 €$
Der vorliegende Band enthält die Vorschläge zur gesetzlichen Neuordnung des internationalen Privatrechts der Gesellschaften. Diese wurde von der durch die 2. Kommission des Deutschen Rates für Internationales Privatrecht eingesetzten Spezialkommission für das internationale Gesellschaftsrecht erarbeitet. Die Einsetzung der Kommission sowie deren Beratungen erfolgten aus Anlass der gesellschaftsrechtlichen Urteile des EuGH zur Niederlassungsfreiheit der Gesellschaften. Diese machten eine Neukonzeption des internationalen Gesellschaftsrechts erforderlich.

Der von der Kommission erstellte Vorschlag einer EG-Verordnung, hilfsweise einer Regelung im deutschen EGBGB, über das internationale Gesellschaftsrecht hat zum Ziel, die im Gefolge der EuGH-Rechtsprechung notwendige Neuordnung dieses Rechtsgebietes anzustoßen und entstandene Rechtsunsicherheit zu beseitigen. Veröffentlicht werden die dem deutschen Bundesjustizminister unterbreiteten Vorschläge für eine europäische und hilfsweise für eine deutsche Regelung, samt den für die Kommission erstatteten Gutachten und Sitzungsberichten. Die Vorschläge sind wegen der europaweiten Bedeutung des Themas in deutscher, englischer und französischer Sprache verfasst.

Hans Jürgen Sonnenberger Geboren 1933; 1969 Habilitation; 1972-86 Professor an der Universität Augsburg; $1986-2002$ Direktor des Instituts für Internationales Recht, Rechtsvergleichung an der Ludwig-Maximilians-Universität München; seit 2002 emeritierter Professor.
Jetzt bestellen:

https://mohrsiebeck.com/buch/vorschlaege-und-berichte-zur-reform-des-europaeischen-und-deutschen-internationalengesellschaftsrechts-9783161512940?no_cache=1

order@mohrsiebeck.com

Telefon: +49 (0)7071-923-17

Telefax: $+49(0) 7071-51104$ 